\title{
Functional Independence Measure Penderita Cedera Servikal
}

\author{
M. Z. Arifin, Jefri Henky \\ Departemen Bedah Saraf Fakultas Kedokteran Universitas Padjadjaran \\ Rumah Sakit Dr. Hasan Sadikin Bandung
}

\begin{abstract}
Abstrak
Cedera servikal merupakan salah satu cedera tulang belakang terbanyak pada penderita trauma. Di Amerika Serikat tahun 2008 dari 100.000 kasus cedera tulang belakang, 2/3 merupakan kasus cedera servikal. Penilaian awal dilakukan berdasarkan American Spinal Cord Injury Association (ASIA) Impairment Score, sedangkan hasil setelah penatalaksanaannya sering diabaikan untuk evaluasi keberhasilan ahli di rumah sakit. Tujuan penelitian untuk mengetahui nilai functional independence measure (FIM) penderita cedera servikal dengan manajemen konservatif dan korelasinya dengan usia, jenis kelamin, jenis trauma, onset trauma, abnormalitas tulang servikal, lesi cervical spine, dan ASIA Impairment Score. Dilakukan studi kohor prospektif pada semua pasien cedera servikal yang memenuhi kriteria inklusi di Departemen Bedah Saraf Rumah Sakit (RS) Dr. Hasan Sadikin Bandung. Subjek dikelompokkan berdasarkan usia, jenis kelamin, trauma tunggal/multipel, akut/kronik, abnormalitas tulang servikal, lesi komplet/inkomplet, ASIA Impairment Score, dan komplikasi awal cedera. Pada penderita dilakukan penilaian FIM di Poliklinik Bedah Saraf. Data dianalisis menggunakan uji-t dan uji chi-kuadrat dengan $p<0,05$. Terdapat 17 penderita cedera servikal yang dirawat di Departemen Bedah Saraf RS Dr. Hasan Sadikin Bandung periode April 2009-April 2010. Observasi kohor prospektif nilai FIM rata-rata penderita cedera servikal adalah $4 \pm 1,63$. Analisis chi-kuadrat menyatakan bahwa tidak terdapat hubungan usia $(p=0,064)$, jenis kelamin $(p=0,144)$, jenis trauma penyerta $(p=0,959)$, onset cedera $(p=0,220)$, abnormalitas tulang servikal $(p=0,869)$ dengan besarnya nilai FIM pasien cedera servikal. Terdapat hubungan jenis lesi cervical spine $(\mathrm{p}=0,037)$, ASIA Impairment Score $(\mathrm{p}<0,001)$ dengan besarnya nilai FIM penderita cedera servikal. Simpulan, jenis lesi cervical spine dan ASIA Impairment Score memiliki hubungan bermakna dengan besarnya nilai FIM penderita 3 bulan pascacedera servikal. [MKB. 2013;45(3):180-6]
\end{abstract}

Kata kunci: ASIA Impairment Score, cedera servikal, functional independence measure

\section{Functional Independence Measure in Patients with Cervical Spine Injury}

\begin{abstract}
Cervical spine injury is one of the most common spinal cord injuries in trauma patients. From 100,000 spinal cord injury cases reported in the United States of America (2008), 2/3 involved cervical spine injury. American Spinal Cord Injury Association (ASIA) Impairment Score is used as an initial assessment but further prognostic outcome of these patients is often not paid enough attention. The objective of this study was to find the value of functional independence measure (FIM) cervical spine injury patients with conservative management and correlation with age, sex, type of trauma, onset of trauma, cervical bone abnormalities, type of spinal lesion and ASIA Impairment Score. A prospective cohort study was performed to all patients with cervical spine injury which fullfil the inclusion criteria treated in Neurosurgery Department of Dr. Hasan Sadikin Hospital Bandung. The subjects were classified based on age, sex, single/multiple trauma, acute/chronic, cervical bone abnormalities, complete/incomplete lesion, ASIA impairment score and initial complication. The patients were performed to FIM examination in Outpatient clinic of Neurosurgery. T-test and chi-square test with $\mathrm{p}<0.05$ were done to analyze the data. There were 17 cervical spine injury patients treated in Neurosurgery Department of Dr. Hasan Sadikin Hospital Bandung during April 2009-April 2010. The average FIM value of cervical spine injury in those patients was $4 \pm 1.63$ by cohort prospective study. There were no correlation between FIM value with age $(\mathrm{p}=0.064)$, sex $(\mathrm{p}=0.144)$, type of trauma $(p=0.959)$, onset of trauma $(p=0.220)$ and cervical bone abnormalities $(p=0.869)$. We found a significant correlation between FIM value with type of cervical spine lesion $(\mathrm{p}=0.037)$ and ASIA Impairment Score $(\mathrm{p}<0.001)$ in cervical spine patients. In conclusion, type of cervical spine lesion and ASIA impairment score have significant correlation with FIM value of patients in 3 months after cervical injury.[MKB. 2013;45(3):180-6]
\end{abstract}

Key words: ASIA impairment score, cervical spine injury, functional independence measure

Korespondensi: Dr. M. Z. Arifin, dr., Sp.BS(K), Departemen Bedah Saraf Fakultas Kedokteran Universitas PadjadjaranRumah Sakit Dr. Hasan Sadikin Bandung, mobile 0811221325 e-mail ns-mspu@indo.net.id 


\section{Pendahuluan}

Cedera servikal adalah cedera tulang belakang yang paling sering dapat menimbulkan kecacatan dan kematian, dari beberapa penelitian ternyata terdapat korelasi tingkat cedera servikal dengan morbiditas dan mortalitas, artinya semakin tinggi tingkat cedera servikal maka semakin tinggi pula morbiditas dan mortalitasnya. ${ }^{1-3}$

Sebanyak $10 \%$ penderita dengan penurunan kesadaran yang dikirim ke IGD (Instalasi Gawat Darurat) oleh karena kecelakaan lalu lintas selalu mendapat cedera servikal, baik cederanya pada tulang servikal, jaringan penunjang, dan cedera pada cervical spine. Kecelakaan lalu lintas dan terjatuh adalah penyebab sebagian besar fraktur tulang servikal. Trauma pada servikal subaksis (C3-7) lebih umum terjadi dibandingkan dengan $\mathrm{C} 1$ dan $\mathrm{C} 2$, dan potensial menjadi trauma yang perlu banyak perhatian. Hampir selalu dipikirkan bahwa akan terjadi trauma servikal pada penderita dengan riwayat kecelakaan kendaraan bermotor kecepatan tinggi, trauma pada wajah dan kepala yang signifikan, terdapat defisit neurologis, nyeri pada leher, dan trauma multipel. ${ }^{4-6}$

Secara anatomis tulang belakang merupakan struktur yang bersifat fleksibel dan dibentuk oleh tulang-tulang yang tidak beraturan yang disebut vertebra, masing-masing dipisahkan oleh diskus intervertebralis. Kolumna vertebralis adalah pilar utama tubuh yang berfungsi melindungi medula spinalis serta menunjang berat kepala dan batang tubuh yang diteruskan ke tulang-tulang paha dan tungkai bawah. ${ }^{7-11}$

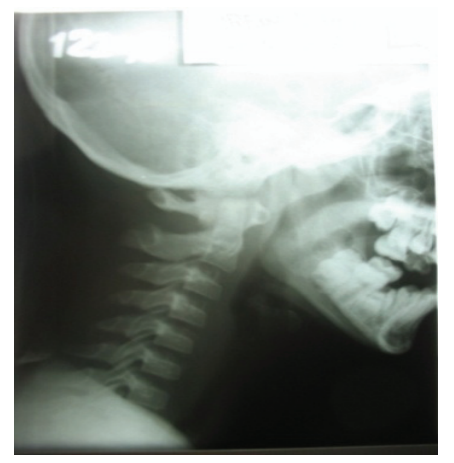

\section{Gambar Foto Rontgen Lateral Tulang Servikal Normal}

Anatomi normal vertebra servikal terdiri atas tujuh tulang vertebra yang dipisahkan oleh diskus intervertebralis dan dihubungkan oleh jaringan ligamen yang kompleks. Jaringan ligamen ini akan mengakibatkan tulang-tulang dapat bekerja sebagai satu kesatuan unit yang utuh. Vertebra servikal memiliki ciri-ciri tiap prosesus tranversus yang mempunyai foramen prosesus tranversus untuk arteri dan vena vertebralis, namun arteri vertebralis hanya melalui prosesus transversus C1-6. . $^{71}$

Penelitian ini bertujuan untuk mengetahui deskripsi nilai functional independence measure (FIM) dan korelasi nilai FIM dengan usia, jenis kelamin, jenis trauma, onset trauma, abnormalitas tulang servikal, lesi cervical spine, dan juga American Spinal Cord Injury Association (ASIA) Impairment Score pada penderita cedera servikal yang dirawat dengan manajemen konservatif di Departemen Bedah Saraf RS Dr. Hasan Sadikin Bandung.

Penelitian ini diharapkan dapat bermanfaat sebagai data untuk evaluasi keberhasilan terapi penderita cedera servikal yang dirawat memakai manajemen konservatif di Departemen Bedah Saraf RS Dr. Hasan Sadikin Bandung dan dapat digunakan sebagai referensi bagi peneliti lainnya.

\section{Metode}

Penelitian ini mempergunakan kohor prospektif yaitu melaksanakan observasi atau pengamatan perjalanan penyakit tanpa dilakukan intervensi penderita cedera servikal yang dirawat dengan manajemen konservatif di Departemen Bedah Saraf Rumah Sakit Dr. Hasan Sadikin Bandung periode April 2009-April 2010. Berdasarkan data rekam medis yang diperoleh, maka penderita diidentifikasi alamat dan kepatuhannya untuk kontrol di Poliklinik Bedah Saraf serta dilatih sesuai prosedur di bagian Rehabilitasi Medik RS Dr. Hasan Sadikin Bandung. Penderita diseleksi mempergunakan kriteria inklusi yaitu penderita yang dirawat dengan cara manajemen konservatif serta dipulangkan dalam keadaan hidup, kontrol teratur di Poliklinik Bedah Saraf Rumah Sakit Dr. Hasan Sadikin Bandung, dan mengikuti latihan teratur di Bagian Rehabilitasi Medik Rumah Sakit (RS) Dr. Hasan Sadikin Bandung, berdomisili di Jawa Barat, dapat dihubungi, dan bersedia datang untuk penilaian FIM ke Departemen Bedah Saraf RS Dr. Hasan Sadikin Bandung. Kriteria eksklusi yaitu penderita dengan kesadaran yang menurun, datang dalam kondisi syok hemoragik, mengalami deformitas tulang ekstremitas, riwayat trauma yang tidak diketahui, dirawat dengan manajemen operatif, tidak memiliki data lengkap yang dapat dihubungi dan menolak segala tindakan (pulang paksa) di Departemen Bedah Saraf RS Dr. Hasan Sadikin Bandung.

Variabel tergantung adalah nilai FIM penderita cedera servikal, sedangkan variabel bebas yaitu 
Tabel 1 Functional Independence Measure Penderita Cedera Servikal

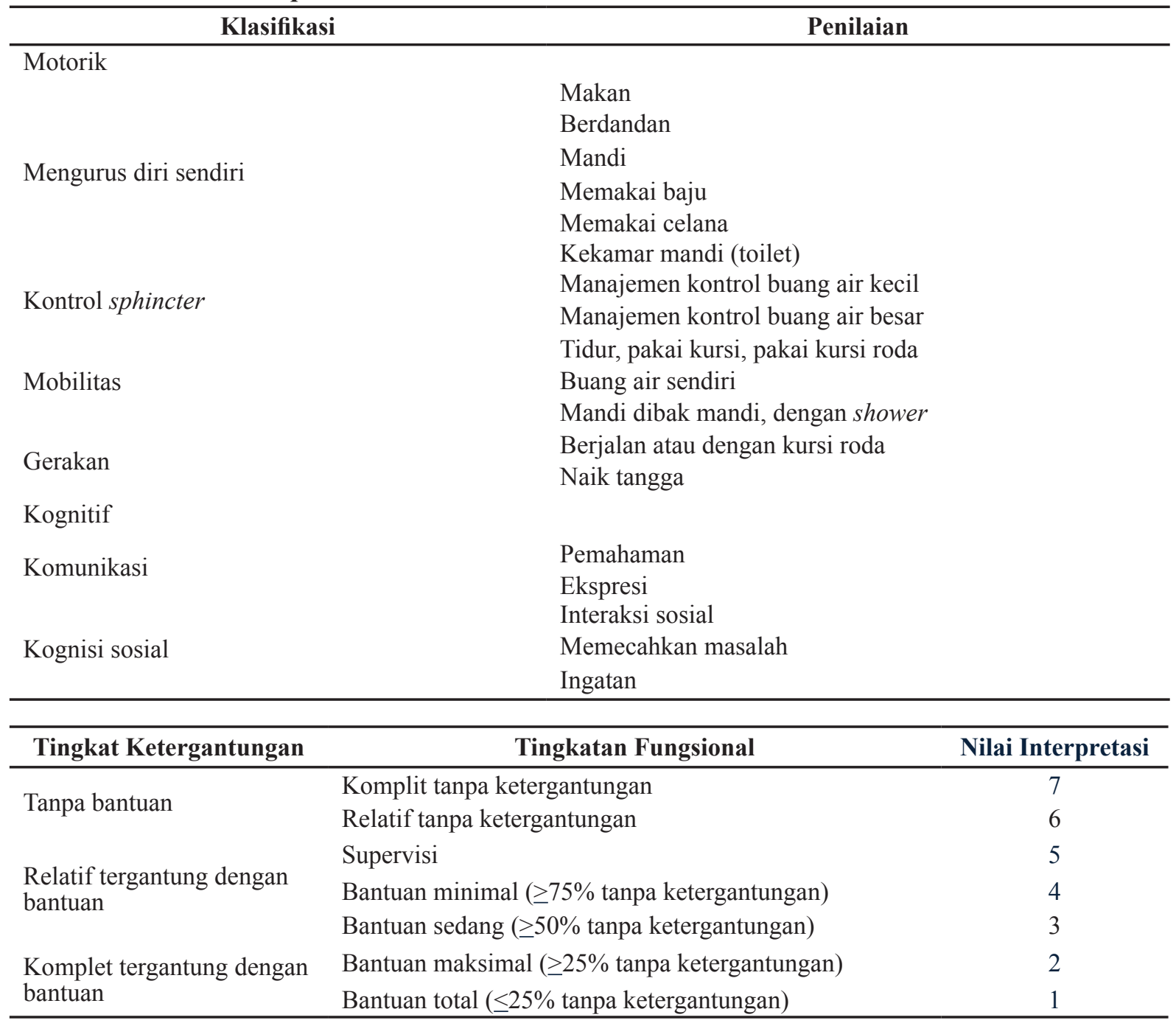

Sumber: Van Middendrop dkk., ${ }^{9}$ Chan dan Chan $^{10}$

usia, jenis kelamin, jenis trauma, onset trauma, abnormalitas tulang servikal, lesi cervical spine, dan ASIA Impairment Score.

Sampel yang telah teridentifikasi dari Bagian Rekam Medik Rumah Sakit Dr. Hasan Sadikin Bandung dikelompokkan berdasarkan usia yaitu $<1$ tahun, 1-10 tahun, 11-20 tahun, 21-30 tahun, 31-40 tahun, 41-50 tahun, 51-60 tahun, dan $>60$ tahun; jenis kelamin; jenis trauma yang terjadi yaitu tunggal dan multipel; onset terjadi trauma yaitu akut (1-3 hari), subakut (4-14 hari), dan kronik ( $>14$ hari); klasifikasi abnormalitas tulang servikal antara lain compression fracture (fraktur vertebra yang melibatkan segmen anterior dan middle), burst fracture (fraktur vertebra yang mengenai segmen anterior saja), tear drop fracture (fraktur pada segmen anterior dengan tarikan segmen fraktur), unilateral facet dislocation (dislokasi sendi faset satu sisi), whiplash (cedera jaringan/ligamen di sekitarnya tanpa deformitas vertebra), bilateral facet fracture dislocation (dislokasi sendi faset dua sisi), cervicothoracic junction injury (cedera vertebra servikal-torakal) dan kombinasi burst fracture dengan teardrop fracture; lesi cervical spine antara lain komplet (motorik dan sensorik terganggu) dan inkomplet (salah satu motorik atau sensorik terganggu); ASIA Impairment Score yaitu tipe A (motorik dan sensorik terganggu/hilang), tipe B (sensorik normal tetapi motorik terganggu/hilang), tipe $\mathrm{C}$ (motorik terganggu dengan kekuatan $<3$ ), tipe $\mathrm{D}$ (motorik terganggu dengan kekuatan $>3$ ), dan tipe $\mathrm{E}$ (motorik dan sensorik normal). ${ }^{7-10}$

Penderita/keluarga yang dihubungi diminta 
Tabel 2 Hubungan Nilai FIM Penderita Cedera Servikal dengan Usia

\begin{tabular}{llllllll}
\hline \multirow{2}{*}{ Usia } & \multicolumn{7}{c}{ Nilai FIM Penderita Cedera Servikal } \\
\cline { 2 - 8 } & $\mathbf{1}$ & $\mathbf{2}$ & $\mathbf{3}$ & $\mathbf{4}$ & $\mathbf{5}$ & $\mathbf{6}$ & $\mathbf{7}$ \\
\hline$<1$ & 0 & 0 & 0 & 0 & 0 & 0 & 0 \\
$1-10$ & 0 & 0 & 0 & 0 & 0 & 0 & 0 \\
$11-20$ & 0 & 0 & 0 & 1 & 1 & 0 & 0 \\
$21-30$ & 0 & 0 & 3 & 0 & 0 & 1 & 0 \\
$31-40$ & 0 & 0 & 4 & 0 & 1 & 0 & 1 \\
$41-50$ & 0 & 0 & 0 & 1 & 0 & 0 & 0 \\
$51-60$ & 0 & 0 & 2 & 0 & 1 & 0 & 1 \\
$>60$ & 0 & 0 & 0 & 0 & 0 & 0 & 0 \\
Jumlah & 0 & 0 & 9 & 2 & 3 & 1 & 2 \\
\hline
\end{tabular}

* Nilai $\mathrm{p}=0,064$

untuk datang ke Departemen Bedah Saraf RS Dr. Hasan Sadikin Bandung untuk dilakukan penilaian FIM. Penilaian ini dilakukan oleh satu ahli bedah saraf dari subdivisi Spine Departemen Bedah Saraf Rumah Sakit Dr. Hasan Sadikin Bandung untuk dilaksanakan homogenisasi data penilaian. Penderita dianamnesis tentang motivasi, aktivitas, kemandirian, dan juga interaksi sosial di rumah, kemudian dibuktikan melalui pemeriksaan fisis dan uji fisis berdasarkan kriteria FIM pada tabel di bawah ini. Data kepatuhan penderita untuk mengikuti latihan di Bagian Rehabilitasi Medik RS Dr. Hasan Sadikin Bandung juga digunakan untuk dapat membuktikan kemajuan pengobatan penderita.

Data penelitian dianalisis dengan uji-t dan uji chi-kuadrat dengan nilai $\mathrm{p}<0,05$ sebagai nilai yang bermakna. Penderita diperlakukan sebagai penderita berobat jalan ke Poliklinik Departemen Bedah Saraf RS Dr. Hasan Sadikin Bandung dan diberi penjelasan tantang skala ketidakmampuan yang dimilikinya.

\section{Hasil}

Berdasarkan hasil data periode April 2009-April
2010, terdapatnya 17 penderita cedera servikal yang dirawat dengan manajemen konservatif di Departemen Bedah Saraf RS Dr. Hasan Sadikin Bandung. Semua penderita tersebut pulang ke rumah dalam kondisi hidup dan evaluasi 3 bulan pascacedera servikal masih dalam kondisi hidup. Observasi kohor prospektif untuk menentukan nilai FIM rata-rata penderita cedera servikal yang dirawat dengan manajemen konservatif adalah $4 \pm 1,63$ yang artinya penderita cedera servikal rata-rata membutuhkan bantuan minimal yaitu $\geq 75 \%$ tanpa ketergantungan.

Tidak terdapat hubungan usia dengan nilai FIM pada penderita cedera servikal $(\mathrm{p}=0,064)$, sedangkan sebaran datanya dapat diartikan bahwa hampir seluruh penderita dari semua golongan usia tidak mempunyai ketergantungan komplet (FIM 1-2), bahkan sekitar 2/17 penderita tanpa ketergantungan atau bantuan (FIM 7) (Tabel 2).

Tidak terdapat hubungan antara jenis kelamin dan nilai FIM penderita cedera servikal $(p=0,144)$. Cedera servikal tersering pada laki-laki dengan nilai FIM terendah FIM 3 atau 50\% bergantung pada bantuan dan nilai FIM tertinggi adalah FIM 7 atau komplet tanpa bantuan.

Hampir semua yaitu $15 / 17$ penderita cedera servikal ini terjadi secara tunggal dan selebihnya

Tabel 3 Hubungan Nilai FIM Penderita Cedera Servikal dengan Onset Trauma

\begin{tabular}{llllllll}
\hline \multirow{2}{*}{ Onset Trauma } & \multicolumn{7}{c}{ Nilai FIM Penderita Cedera Servikal } \\
& $\mathbf{1}$ & $\mathbf{2}$ & $\mathbf{3}$ & $\mathbf{4}$ & $\mathbf{5}$ & $\mathbf{6}$ & $\mathbf{7}$ \\
\hline Akut & 0 & 0 & 8 & 0 & 2 & 1 & 2 \\
Subkronik & 0 & 0 & 1 & 0 & 0 & 0 & 0 \\
Kronik & 0 & 0 & 0 & 2 & 1 & 0 & 0 \\
Jumlah & 0 & 0 & 9 & 2 & 3 & 1 & 2 \\
\hline
\end{tabular}

* Nilai $\mathrm{p}=0,220$ 
M. Z. Arifin: Functional Independence Measure Penderita Cedera Servikal

Tabel 4 Hubungan Nilai FIM Penderita Cedera Servikal dengan Abnormal Tulang Servikal

\begin{tabular}{llllllll}
\hline \multicolumn{1}{c}{ Tulang Servikal } & \multicolumn{7}{c}{ Nilai FIM Penderita Cedera Servikal } \\
\cline { 2 - 7 } & $\mathbf{1}$ & $\mathbf{2}$ & $\mathbf{3}$ & $\mathbf{4}$ & $\mathbf{5}$ & $\mathbf{6}$ & $\mathbf{7}$ \\
\hline Fraktur kompresi & 0 & 0 & 3 & 0 & 0 & 0 & 0 \\
Fraktur burst & 0 & 0 & 1 & 0 & 1 & 0 & 0 \\
Fraktur tear drop & 0 & 0 & 1 & 0 & 0 & 0 & 0 \\
Whiplash injury & 0 & 0 & 1 & 2 & 2 & 1 & 0 \\
Dislokasi faset unilateral & 0 & 0 & 2 & 0 & 0 & 0 & 0 \\
Dislokasi faset bilateral & 0 & 0 & 1 & 0 & 0 & 0 & 1 \\
Fraktur burst dan Fraktur teardrop & 0 & 0 & 0 & 0 & 0 & 0 & 1 \\
Jumlah & 0 & 0 & 9 & 2 & 3 & 1 & 2 \\
\hline
\end{tabular}

* Nilai $\mathrm{p}=0,869$

2/17 penderita merupakan cedera multipel. Dari analisis chi-kuadrat nilai FIM dengan jenis trauma ini tidak mempunyai hubungan yang bermakna $(\mathrm{p}=0,959)$. Namun hasilnya yaitu $7 / 17$ penderita cedera servikal ini memerlukan bantuan $50 \%$ dari keluarga atau orang di sekitarnya.

Penderita cedera servikal yang datang ke rumah sakit pada fase akut $(<72$ jam $)$ memilikinilai FIM 3 atau 50\% memerlukan bantuan keluarga sebanyak 8/17 penderita dan dapat mempunyai nilai FIM 7 atau komplet tanpa ketergantungan sebanyak $2 / 17$ penderita. Keadaan tersebut berarti fase akut kejadian cedera servikal memberikan peluang nilai FIM yang lebih baik, walaupun ada beberapa faktor lain yang memengaruhi seperti jenis cedera abnormalitas tulang servikal akibat cedera dan lesi cervical spine. Dari analisis chikuadrat tidak terdapat hubungan onset cedera (akut-subakut-kronik) dengan nilai FIM penderita cedera servikal ( $\mathrm{p}=0,220$; Tabel 3).

Abnormalitas tulang servikal tidak memiliki hubungan yang bermakna dengan nilai FIM pada penderita cedera servikal $(p=0,869)$. Hal ini secara statistik dianggap wajar karena nilai FIM hampir tersebar merata pada semua tipe abnormal tulang servikal (Tabel 4).

Sebagian besar 9/17 penderita lesi komplet cervical spine mempunyai nilai FIM 3 yaitu 50\% membutuhkan bantuan keluarga, sedangkan 7/17 penderita lesi inkomplet mempunyai nilai FIM 4-7 yaitu $>75 \%$ tanpa ketergantungan sampai komplet tanpa ketergantungan. Secara statistik terdapat hubungan antara jenis lesi cervical spine dan besarnya nilai FIM penderita cedera servikal $(p=0,037)$.

Sebagian besar 9/17 penderita tipe A ASIA Impairment Score mempunyai nilai FIM 3, hal ini membuktikan bahwa lesi komplet dengan kehilangan motorik dan sensorik pada penderita cedera servikal akan membutuhkan bantuan dari keluarga $>50 \%$, sedangkan $2 / 17$ penderita tipe $\mathrm{E}$ ASIA Impairment Score mempunyai nilai FIM

Tabel 5 Hubungan Nilai FIM Penderita Cedera Servikal dengan ASIA Impairment Score

\begin{tabular}{|c|c|c|c|c|c|c|c|}
\hline \multirow{2}{*}{ ASIA Impairment Score } & \multicolumn{7}{|c|}{ Nilai FIM Penderita Cedera Servikal } \\
\hline & 1 & 2 & 3 & 4 & 5 & 6 & 7 \\
\hline Tipe A & 0 & 0 & 9 & 0 & 0 & 0 & 0 \\
\hline Tipe B & 0 & 0 & 0 & 1 & 0 & 0 & 0 \\
\hline Tipe C & 0 & 0 & 0 & 1 & 3 & 0 & 0 \\
\hline Tipe D & 0 & 0 & 0 & 0 & 0 & 1 & 0 \\
\hline Tipe E & 0 & 0 & 0 & 0 & 0 & 0 & 2 \\
\hline Jumlah & 0 & 0 & 9 & 2 & 3 & 1 & 2 \\
\hline
\end{tabular}

* Nilai $\mathrm{p}=0,000$ 
7 yaitu komplet tanpa ketergantungan. Secara statistik terdapat hubungan ASIA Impairment Score dengan besarnya nilai FIM penderita cedera servikal ( $\mathrm{p}=0,000$; Tabel 5).

\section{Pembahasan}

Tujuan penelitian ini untuk mengetahui deskripsi nilai FIM penderita cedera servikal yang dirawat dengan manajemen konservatif dan korelasi nilai FIM terhadap usia, jenis kelamin, jenis trauma, onset trauma, abnormalitas tulang servikal, lesi cervical spine, dan juga ASIA Impairment Score. Meskipun subjek yang terkumpul tersebut sedikit, penelitian ini juga mampu memberikan informasi outcome penderita cedera servikal yang dirawat memakai manajemen konservatif di Departemen Bedah Saraf RS Dr. Hasan Sadikin Bandung periode April 2009-April 2010.

Nilai FIM penderita cedera servikal yang dirawat dengan cara manajemen konservatif pada penelitian ini $4 \pm 1,63$ yang berarti penderita cedera servikal rata-rata membutuhkan bantuan minimal sebesar $\geq 75 \%$ tanpa ketergantungan. Menurut Jongjit dkk.,${ }^{12}$ nilai FIM penderita cedera servikal ditentukan secara individual yang dipengaruhi oleh usia, berat badan dan juga tinggi badan, jenis trauma, onset trauma, lesi cervical spine, keparahan spastisitas selama perawatan, motivasi penderita dan keluarga, lingkungan di sekitarnya, premorbid gaya hidup, pekerjaan, latar belakang pendidikan, serta status keuangan. ${ }^{12,13}$

Pada penelitian ini usia, jenis kelamin, jenis trauma, onset trauma, serta abnormalitas tulang servikal tidak mempunyai korelasi dengan nilai FIM. Hal ini disadari karena pengaruh faktorfaktor yang di atas sehingga menjadi bias untuk beberapa subjek serta sebaiknya diminimalisasi dengan skrining kriteria inklusi dan eksklusi yang lebih lengkap.

Peran dari Bagian Rehabilitasi Medik yaitu untuk mengurangi tingkat ketergantungan danjuga kecacatan penderita sangatlah diharapkan, oleh karena latihan yang diberikan dapat memperbaiki gangguan aktivitas harian penderita antara lain pada gangguan motorik, sensorik, bowel, dan juga bladder. ${ }^{14}$ Jongjit dkk. ${ }^{12}$ melaporkan bahwa 15 penderita lesi inkomplet cervical spine, sebanyak $39 \%$ mempunyai peningkatan nilai FIM berupa perbaikan manajemen buang air besar, mobilitas, dan gerakan (FIM 4). ${ }^{12}$

Pada penelitian sebagian besar lesi komplet cervical spine memiliki nilai FIM 3 yaitu 50\% membutuhkan bantuan dari keluarga, sedangkan 7/17 penderita lesi inkomplet cervical spine mempunyai nilai FIM 4-7 yaitu $>75 \%$ sampai komplet tanpa ada ketergantungan. Persentase ini merupakan hasil kepatuhan penderita menjalani rehabilitasi selama perawatan di Departemen Bedah Saraf RS Dr. Hasan Sadikin Bandung dan hasil kerjasama dengan Bagian Rehabilitasi Medik Rumah Sakit Dr. Hasan Sadikin Bandung. Nilai FIM secara statistik mempunyai hubungan yang signifikan dengan jenis lesi cervical spine.

Tipe A ASIA Impairment Score memiliki nilai FIM 3 sebanyak 9/17 penderita yaitu lesi komplet dengan kehilangan motorik dan sensorik akan membutuhkan bantuan keluarga $>50 \%$, sedangkan 2/17 tipe E ASIA impairment score memiliki nilai FIM 7 yaitu komplet tanpa ketergantungan. Dari data tersebut berarti ASIA Impairment Score memiliki hubungan yang signifikan dengan nilai FIM pada penderita cedera servikal. Keadaan ini terbukti secara statistik memakai uji chi-kuadrat. Penelitian lain di Bagian Terapi Okupasi RS Tai Po, Hongkong melaporkan bahwa 24 kasus cedera servikal tipe D dan 9 kasus cedera servikal tipe A ASIA Impairment Score yang diterapi, memiliki nilai FIM 3. Nilai FIM 3 tersebut tidak mengalami perubahan sejak penderita masuk, dirawat, 1 bulan pascaperawatan, serta 3 bulan pascaperawatan, serta hanya terbatas pada kasus akut cedera servikal. ${ }^{10}$ Untuk itu disarankan agar melakukan penilaian FIM saat penderita masuk, dirawat dan 1, 3, 6 bulan pascaperawatan rumah sakit sehingga dapat dibandingkan.

Jenis lesi cervical spine dan ASIA Impairment Score pada penderita cedera servikal mempunyai hubungan bermakna dengan nilai FIM penderita 3 bulan pascacedera servikal. Dengan mengetahui kedua nilai variabel tersebut dapat ditentukan angka keberhasilan terapi dan prognosis outcome (nilai FIM) penderita cedera servikal yang dirawat dengan manajemen konservatif.

\section{Daftar Pustaka}

1. Milby AH, Halpern CH, Guo W, Stein SC. Prevalence of cervical spinal injury in trauma. Neurosurg Focus. 2008;25(5):E1-10.

2. Van den Berg MEL, Castellote JM, Fernandez IM, Cuesta de Pedro J. Incidence of spinal cord injury worldwide: asystematic review. Neuroepidemiology. 2010;34(7):184-92.

3. Ning GZ, Yu TQ, Feng SQ, Zhow XH, Ban DX, Liu Y, dkk. Epidemiology of traumatic spinal cord injury in Tianjin, China. Spinal Cord. 2011;49(3):386-90.

4. Grundy D, Swain A. ABC of spinal cord injury. Edisi ke-4. London: BMJ Publishing; 2002 .

5. Weishaupt N, Silasi G, Colbourne F, Fouad $\mathrm{K}$. Secondary damage in the spinal cord after motor cortex injury in rats. J Neurotrauma. 
2010;27(5):1387-97.

6. Holly LT, Kelly DF, Counelis GJ, Blinman T, McArthur DL, Cryer G. Cervical spine trauma associated with moderate and severe head injury: incidence, risk factors, and injury characteristics. J Neurosurg. 2002; 96(3):285-91.

7. Stewart B, Dinsker D. The unstable spine fracture in cervical, thoracic, lumbar and sacral region. USA: Lippincott; 2002.

8. El Masri. Traumatic spinal cord injury: the relationship between pathology and clinical implications. Trauma. 2006;8(2):29-46.

9. Van Middendorp JJ, Hosman AJF, Donders ART, Pouw MH, Ditunno JF, Curt A. A clinical prediction rule for ambulation outcomes after traumatic spinal cord injury: a longitudinal cohort study. Lancet. 2011; 377(10):1004-10.

10. Chan SCC, Chan APS. Rehabilitation outcomes following traumatic spinal cord injury in tertiary spinal cord injury centre: a comparison with an international standard. Spinal Cord. 2005;43(5):489-98.

11. Wadhwa R, Shamieh S, Haydel J, Caldito G, Williams M, Nanda A. The role of flexion and extension computed tomography with reconstruction in clearing the cervical spine in trauma patients: a pilot study. J Neurosurg. 2011;14(3):341-7.

12. Jongjit J, Sutharom W, Komsopapong L, Numpechitra N, Songjakkaew P. Functional independence and rehabilitation outcome in traumatic spinal cord injury. Southeast Asian J Trop Med Public Health. 2004;35(4):980-5.

13. Post WM, Dallmeijer AJ, Augenot ELD, Van Asbeck FWA, Van Der Woude LHV. Duration and functional outcome of spinal cord injury rehabilitation in the Netherlands. J Rehabil Res Dev. 2005;42(3):75-86.

14. Marino RJ. Domain of outcomes in spinal cord injury for clinical trials to improve neurological function. J Rehabil Res Dev. 2007;44(1):113-22. 